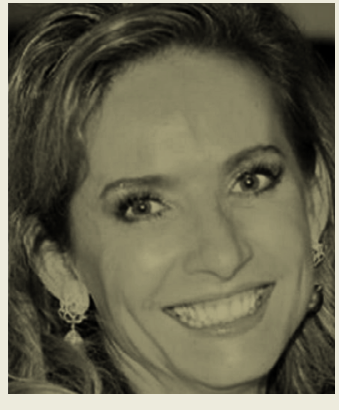

\title{
ÉTICA NOS ALGORITMOS: A NOVA FRONTEIRA DA GOVERNANÇA
}

Os algoritmos são elemento-chave nas sociedades da informação. Cada vez mais a humanidade depende dos algoritmos para melhoria do bem-estar social. Decisões e escolhas são baseadas em algoritmos que aconselham e às vezes até mesmo decidem pelos seres humanos sobre como os dados devem ser interpretados e quais ações devem ser tomadas. Os exemplos são abundantes. Basta lembrar que Facebook, Google, YouTube, Instagram e Amazon usam algoritmos para direcionar o que os usuários irão ver.

Como garantir que os algoritmos não tenham um viés subjetivo que afete o resultado em prol de determinado grupo de indivíduos, gerando discriminação, por exemplo? Algoritmo pode ser entendido como uma construção matemática, com entendimentos específicos voltados à implementação ou solução de uma tarefa ou de um problema. Em teoria, ele é ético e imparcial. A realidade demonstra, porém, que o viés existe e é um grande problema. Os algoritmos são movidos por dados e o viés está exatamente nos dados que são utilizados na construção do sistema de aprendizado da inteligência artificial pelos seres humanos. Os algoritmos utilizam esses dados para classificar e agrupar pessoas, criar perfis, conhecer preferências e comportamentos, rastrear contatos, indicar produtos e serviços, recomendar pessoas. Os vieses nos dados são, assim, reproduzidos e até amplificados pelas recomendações de conteúdo de diferentes plataformas.

O que é possível fazer para evitar essa multiplicação de vieses? A Lei Geral de Proteção de Dados Pessoais (LGPD) trata, em parte, de regular o tratamento de dados pessoais e, com isso, do uso desses dados pelos sistemas de decisão algorítmica. Assim, a legislação permite que o titular dos dados solicite "a revisão de decisões tomadas unicamente com base em tratamento automatizado de dados pessoais que afetem seus interesses, incluídas as decisões destinadas a definir o seu perfil pessoal, profissional, de consumo e de crédito ou os aspectos de sua personalidade" (art. 20). A LGPD coloca em xeque a questão da ética dos algoritmos e cria uma cultura centrada na proteção de dados dos usuários.

Combater a falta de transparência nos algoritmos é uma tarefa árdua, porque cada viés nos dados algorítmicos pode ser único. Além disso, grande parte das pessoas não sabe sequer como são estabelecidas as decisões automatizadas pelos algoritmos. A solução mais óbvia é tornar os algoritmos transparentes, facilitando identificar os vieses. O TikTok, por exemplo, quebrou recentemente a prática da falta de transparência, ao abrir seus algoritmos de classificação e compartilhamento de vídeos.

As implicações éticas ligadas aos algoritmos são questões recentes, mas que estão crescendo exponencialmente. A conduta ética não é mais algo adequado para uma empresa ter, mas uma necessidade real para a construção de um futuro mais justo para toda a sociedade. Sem a ética, o viés dos algoritmos será cúmplice no aumento das desigualdades sociais e da discriminação. Surge então o compliance nos algoritmos, que monitora questões como a qualidade dos dados, os critérios de seleção de dados, as formas como os dados são tratados e o controle dos resultados do algoritmo. Será que em breve teremos algoritmos verificando a conformidade dos algoritmos? 